\title{
MANAJEMEN PEMBELAJARAN BERBASIS APLIKASI SONY SUGEMA DIGITAL LEARNING SISTEM (S2DLS)
}

\section{Heri Heryana}

Universitas Islam Negeri Sunan Gunung Djati Bandung heryanabalewa@gmail.com

\author{
Nina Nurmila \\ Universitas Islam Negeri Sunan Gunung Djati Bandung \\ ninanurmila@uinsgd.ac.id
}

\begin{abstract}
ABSTRAK
Aplikasi Sony Sugema Digital Learning System adalah sebuah aplikasi yang di buat oleh yayasan Taqwa Cerdas Kreatif dengan tujuan sebagai pendukung proses pembelajaran. Dengan adanya aplikasi ini para peserta didik menemukan cara belajar yang berbeda, mereka dapat belajar dimana saja dan kapan saja menggunakan laptop. Metode yang digunakan dalam penelitian ini adalah pendekatan kualitatif dengan metode deskriptif. Sedangkan teknik pengumpulan data yang digunakan meliputi observasi, wawancara, dan studi dokumentasi. Perencanaan dilakuakan dengan menganalisis data, pengorganisasian melibatkan kepala sekolah beserta jajarannya, kepemimpinan menggunakan model demokratis, pengevaluasian bersifat masukan dan saran. Hasil dari penelitian ini dapat diketahui bahwa aplikasi Sony Sugema Digital Learning Sytem dapat meningkatkan minat belajar peserta didik.
\end{abstract}

Kata kunci: manajemen, pembelajaran, digital

\section{ABSTRACT}

The Sony Sugema Digital Learning System application is an application created by the Taqwa Cerdas Kreatif foundation with the aim of supporting the learning process. With this application, students find different ways of learning, they can learn anywhere and anytime using a laptop. The method used in this research is a qualitative approach with a descriptive method. While the data collection techniques used include observation, interviews, and documentation studies. Planning is done by analyzing data, organizing involves the principal and his staff, leadership uses a democratic model, evaluation is input and suggestions. The results of this study can be seen that the Sony Sugema Digital Learning System application can increase students' interest in learning.

Key words: management, learning, digital 


\section{PENDAHULUAN}

Manusia pada dasarnya adalah manajer, karena dalam kehidupannya sehari-hari setiap manusia selalu melakukan manajemen bagi dirinya sendiri ataupun keluarganya untuk memenuhi kebutuhan keluarga serta merealisasikan tujuan-tujuan yang diinginkan (self management). Para mahasiswa dan mahasiswi setiap hari juga senantiasa harus selalu melakukan manajemen karena setiap mahasiswa itu memiliki tujuan tertentu. Sebagai seorang mahasiswa tentu saja mereka memiliki tujuan belajar yaitu untuk memperoleh ilmu pengetahuan yang dibuktikan dengan dimilikinya ijazah sarjana.

Pemahaman tentang konsep dasar manajemen yang memiliki corak pandang yang berbeda. Dalam hal ini para pakar manajemen memiliki pandangan yang beragam sesuai dengan sasaran yang ingin disampaikan oleh para ahli tersebut. Sedangkan manajemen dalam arti sempit ialah manajemen sekolah yang meliputi kegiatan perencanaan program sekolah/madrasah, pengawas/evaluasi dan sistem informasi sekolah/madrasah. Dari deskripsi di atas dapatlah dipahami bahwa manajemen merupakan suatu seni untuk mengkoordinir sumber daya manusia dan sumber daya lainnya yang ada dalam organisasi untuk mencapai tujuan organisasi yang telah ditentukan sebelumnya dalam proses perencanaan.

Proses pembelajaran pada hakikatnya merupakan proses komunikasi atau penyampaian pesan dari pengantar ke penerima. Pesan berupa materi pelajaran yang dituangkan ke dalam simbol-simbol komunikasi baik verbal (katakata dan tulisan) maupun nonverbal. Pesan inilah yang akan ditangkap oleh peserta didik sebagai sebuah pengetahuan, keterampilan maupun nilai-nilai yang dapat digunakan dalam kehidupan sehari-hari. Agar pesan tersebut disampaikan secara efektif tentu membutuhkan sarana atau media yang memadai (Muhson, 2010).

Peranan guru sangatlah penting saat pembelajaran dilakukan, tanpa peranan guru tidak akan terlaksananya pembelajaran. Metode pembelajaran itu penting dimana metode ini akan membuat pelaksanaan pembelajaran berjalan dengan lancer. Pemilihan metode pembelajaran perlu sesuai karena dalam penggunaan metode ini supaya anak tidak merasa bosan saat berlangsungnya pembelajaran (Hanifah, 2018).

Manajemen pembelajaran adalah ilmu murni terapan dan sistem. Salah satu sistem manajemen pembelajaran adalah sistem yang berkenaan dengan teknologi pendidikan, yang mana teknologi pendidikan ini adalah salah satu sistem yang berhubungan dengan manusia, mesin, gagasan, prosedur dan manajemen. Manajemen pembelajaran menciptakan peluang dan bagaimana murid belajar dan apa yang dipelajari oleh murid tersebut (Syafaruddin \& Nasution, 2005, p. 78).

Manejemen pembelajaran juga merupakan proses menolong murid untuk mencapai pengetahuan, keterampilan, kemampuan dan pemahaman terhadap dunia di sekitar mereka. Konsekuensinya adalah manajemen pembelajaran menciptakan peluang bagaimana murid belajar dan apa yang dipelajari murid. Dengan kata lain, dalam manajemen pembelajaran memunculkan pertanyaan, bagaimana mereka dapat belajar, apa yang mereka pelajari dan dimana mereka mempelajarinya. Untuk mencapai hal yang dimaksud maka diperlukan strategi manajemen efektif di dalam kelas yang secara organisasional pembelajaran atau 
kegiatan belajar mengajar. Guru memiliki kesiapan mengajar, dan murid disiapkan untuk belajar (Nasution, 2000, p. 35).

Menurut Davis peranan guru sebagai manajer dalam proses pengajaran yaitu merencanakan, mengorganisasikan, memimpin, dan mengawasi. Merencanakan disini adalah menyusun tujuan belajar mengajar (pengajaran). Sedangkan mengorganisasikan adalah berhubungan atau menggabungkan seluruh sumber daya belajar mengajar dalam mencapai tujuan secara efektif dan efisien. Memimpin yaitu memotivasi para peserta didik untuk siap menerima materi pelajaran dan mengawasi, yaitu apakah pekerjaan atau kegiatan belajar mengajar mencapai tujuan pengajaran. Karena itu harus ada proses evaluasi pengajaran, sehingga diketahui hasil yang dicapai(Syafaruddin \& Nasution, 2005, p. 75).

Dalam kemajuan ilmu pengetahuan dan teknologi memiliki pengaruh yang sangat besar dalam berbagai bidang kehidupan manusia. Pendidikan sebagai salah satu yang tidak terpisahkan dari proses pendewasaan manusia tentu di satu sisi memiliki andil yang sangat besar bagi pengembangan ilmu pengetahuan dan teknologi tersebut, namun di sisi lain pendidikan juga perlu memanfaatkan kemajuan ilmu pengetahuannya dan teknlogi agar mampu mencapai tujuannya secara efektif dan efisien. Kemajuan ilmu pengetahuan dan teknologi telah berpengaruh terhadap penggunaan alat-alat bantu mengajar di sekolah-sekolah dan lembaga-lembaga pendidikan lainnya (Muhson, 2010, p. 1).

Pendidikan mengalami perkembangan yang sangat pesat pula, diantaranya dengan adanya pembelajaran digital (digital learning). Dengan memanfaatkan perkembangan teknologi informasi dan komunikasi itu, pendidikan dapat menjangkau seluruh lapisa masyarakat. Pendidikan tidak alergi dengan perkembangan ilmu pengetahuan dan teknologi tersebut, namun sebaliknya menjadi subjek atau pelopor dalam pengembangannya. Orang-orang yang berkepentingan dengan pendidikan dituntut untuk memiliki kemampuan memahami teknologi sesuai dengan kebutuhan atau melek teknologi yang disebut juga memiliki literasi teknologi, karena akan berperan dalam kehidupan masa kini dan masa yang akan datang. Akibatnya, dalam dunia pendidikan pada masa kini dan masa yang akan datang ada beberapa kecenderungan antara lain sistem pembelajaran yang semakin berkembang dengan adanya kemudahan untuk menyelenggarakan pendidikan (Munir, 2017, p. 2).

Teknologi digital bukan merupakan hal yang baru datang secara tiba-tiba, tetapi sudah berproses sejak tahun 80an, sehingga sampai abad 21 sekarang ini, disebut era digital. Pada era ini penggunaan teknologi digital sudah menjadi kebutuhan, bukan saja orang dewasa, tetapi juga remaja, bahkan anak dibawah umur sudah mengenal yang namanya Hand Phone (HP). Menggunakan perangkat digital dengan menggunakan media Google, Blog, Email, kita dapat melihat jendela dunia yang berisikan informasi-informasi di seluruh penjuru dunia. Pembelajaran dengan menggunakan teknologi informasi menuntut kreativitas dan kemandirian diri sehingga memungkinkan mengembangkan semua potensi yang dimiliki peserta didik (Yuliana, 2019). Tenaga pendidikan yang berkualitas sebagai guru, dosen, konselor, pamong belajar, widyaiswara, tutor dan sebutan lain yang sesuai dengan kekhusuannya dan peserta didik dengan sangat mudah mencari kebutuhan bahan ajar yang mereka butuhkan (Muhasim, 2017, p. 56). 
Perkembangan teknologi pembelajaran digital yang sangat pesat dan merambah ke seluruh penjuru dunia telah dimanfaatkan oleh berbagai negara, institusi dan ahli untuk berbagai kepentingan termasuk didalamnya untuk pendidikan dan pembelajaran. Proses pembelajaran harus terhindar dari pengaruh buruk teknologi, sehingga diperlukan pembimbingan dan pengawasan kepada peserta didik baik oleh guru maupun orang tua, agar pengaruh positif dari kemajuan teknologi digital ini dapat bermanfaat. Pendidik dan peserta didik dalam proses pembelajaran akan termotivasi menggunakan sebuah sistem teknlogi digital apabila individu tersebut merasa memperoleh manfaat dari keberadaan sistem teknologi tersebut. Perkembangan sistem teknologi digital tidak dapat dipisahkan dengan kegiatan pembelajaran, tetapi hal itu bisa mempengaruhi posistif maupun negatif. Oleh sebab itu dibutuhkan latihan berpikir positif terhadap peserta didik agar kemajuan teknologi digital ini dapat bermanfaat terhadap motivasi(Muhasim, 2017, p. 69).

Pembelajaran digital disebut juga pembelajaran jarak jauh (Distance Learning) yang memanfaatkan teknologi komputer, jaringan komputer dan internet. Pembelajaran digital memungkinkan pembelajar untuk belajar melalui komputer di tempat mereka masing-masing tanpa harus secara fisik pergi mengikuti pelajaran perkuliahan di kelas. Pembelajaran seperti ini juga sering dipahami sebagai suatu bentuk pembelajaran berbasis web yang bisa diakses dari internet di jaringan lokal atau internet (Zufria, 2016).

Pemanfaatan Information Technology and Communication (ICT) juga sangat berpengaruh terhadap kemajuan teknologi pembelajaran digital karena keunggulan dan pemanfaatan ICT dalam pembelajaran dan pengajaran yaitu ICT mampu menciptakan lingkungan belajar yang aktif dan mendorong kemandirian siswa serta dapat meningkatkan minat dalam belajar. Selain itu, pemanfaatan ICT dalam pembelajaran mampu menciptakan proses pembelajaran kolaboratif. Proses pembelajaran kolaboratif ini mengarah kepada adanya interaksi sosial dan komunikasi antara para siswa dan pendidik. Hal ini berdampak posistif terhadap peningkatan pemahaman dan pengetahuan siswa tentang materi pelajaran (Wardani et al., 2020).

Pengembangan pembelajaran digital memerlukaan perencanaan yang hati-hati dan studi kelayakan yang matang agar pengembangan ini mampu menjawab berbagai permasalahan dalam pembelajaran, pendidikan, dunia kerja, dan keilmuan. Terlebih dahulu dilakukan penentuan pembelajaran digital untuk melengkapi keberadaan kurikulum online kemudian menentukan bagaimana cara yang paling baik untuk mengembangkannya. Untuk pengembangan pembelajaran digital diperlukan wawasan yang luas tentang program dalam semua tingkatan pendidikan. Dengan demikian dapat dilihat pelajaran yang mana yang perlu ditambah, diubah, atau diperbaharui. Jika seluruh pembelajaran digital diletakan ke dalam tempatnya, perlu dilihat bagaimana pelajaran individual akan membantu mempertemukan tujuan belajar yang ditetapkan bagi seluruh program (Munir, 2017, p. 56).

Berdasarkan hasil observasi pendahuluan di SMA Alfa Centauri Bandung menunjukan bahwa SMA Alfa Centauri Bandung menerapkan teknologi informasi dalam proses pembelajarannya dan merupakan salah satu lembaga pendidikan yang menerapkan sistem pembelajaran berbasis teknologi informasi dalam 
proses pembelajaran di luar kelas. Para peserta didik di SMA Alfa Centauri Bandung dapat belajar menggunakan teknologi informasi dengan sebuah aplikasi yang dapat dijalankan di laptop, tablet dan bahkan sekarang sedang dikembangkan agar bisa dijalankan di smartphone Android.

SMA Alfa Centauri Bandung sebagai salah satu sekolah swasta unggulan di Bandung lebih menitik beratkan ke arah teknologi digital dalam manajemen proses pendukung kegiatan pendidikannya, terutama dalan proses pembelajarannya. Penggunaan perangkat digital membuat proses evaluasi belajar siswa SMA Alfa Centauri Bandung menjadi lebih praktis dan efisien (tanpa penggunaan kertas atau paperless). Saat pelaksanaan tes, naskah soal akan muncul di layar PC atau Notebook sesuai waktu yang diberikan, siswa tinggal mengerjakan dan memberi jawaban hasil tes dapat langsung diketahui setelah waktu ujian berakhir. SMA Alfa Centauri Bandung juga menjadi sekolah pertama yang mengembangkan aplikasi berbasis android sebagai salah satu sumber belajarnya.

Dalam hal penunjang proses pembelajarannya, SMA Alfa Centauri Bandung mempunyai sebuah sistem pembelajaran berbasis digital atau aplikasi yang bernama S2DLS atau kepanjangan dari Sony Sugema Digital Learning System. Adanya aplikasi ini dapat medorong siswa dalam hal kemandirian belajar dan pendalaman materi bahan ajar, karena dapat belajar kapan saja dan dimana saja baik secara online maupun offline.

Dengan adanya aplikasi S2DLS evaluasi pembelajaran dilakukan secara otomatis melalui proses digital sehingga tidak perlu pengkoreksian secara manual melalui kertas, hasil yang diperoleh akan lebih cepat, akurat dan obyektif, namun di dalam semua kemudahan tersebut pasti ada kekurangan di dalamnya. Peran guru dikembalikan ke fungsi sesungguhnya sebagai pendidik tidak hanya mengajarkan materi pelajaran untuk mencapai target kurikulum (karena semua materi sudah terintegrasi dalam S2DLS) tersebut, namun lebih kepada pemahaman makna, pendalaman materi dan pembelajaran di dalam kehidupan nyata. Oleh karena itu peniliti begitu tertarik untuk mengkaji bagaimanakah manajemen pembelajaran berbasis aplikasi Sony Sugema Digital Learning System ini.

\section{METODE}

Penelitian ini menggunakan metode dekriptif kualitatif, yaitu metode yang bertujuan untuk mendeskripsikan masalah yang terjadi atau berlangsung secara rinci apa adanya. Metode pendekatan kualitatif adalah penelitian yang menghasilkan prosedur analisis yang tidak menggunakan prosedur analisis statistik atau cara kuantifikasi lainnya (Moleong, 2011, p. 6). Penelitian kualitatif didasarkan pada upaya membangun pandangan mereka yang diteliti yang rinci, dibentuk dengan kata-kata, gambaran holistik dan rumit. Maka metode ini akan digunakan peneliti untuk mendeskripsikan hasil penelitian berdasarkan fenomena yang ada. Adapun data dapat berupa hasil pengalaman subyektif dari sumber data tentang manajemen pembelajaran berbasis aplikasi Sony Sugema Digital Learning System (S2DLS) di SMA Alfa Centauri Bandung. 


\section{HASIL DAN PEMBAHASAN}

\section{Latar Alamiah SMA Alfa Centauri Bandung.}

SMA Alfa Centauri Bandung berdiri pada tahun 2003/2004 yang berawal dari sebuah lembaga kursus yang bernama Sony Sugema College (SSC) yang didirikan oleh bapak H. Sony Sugema, MBA melalui yayasan Taqwa Cerdas Kreatif. Pada awal pendiriannya SMA Alfa Centauri Bandung membuka sekolah gratis. Seluruh peserta didik angkatan pertama yang berjumlah 75 orang, adalah siswa dari kelompok masyarakat tidak mampu (dhuafa). Meski tidak dipungut biaya, calon peserta didik yang ingin bersekolah di SMA Alfa Centauri Bandung harus melalui seleksi yang sangat ketat. Mereka yang memiliki kriterialah yang dapat bersekolah di SMA Alfa Centauri yang bermarkas di JI. Diponegoro, No 48, kota Bandung.

Dari mulai pendiriannya sampai sekarang, SMA Alfa Centauri Bandung selalu membuat terobosan baru dalam dunia pendidikan. Terutamanya dalam menjalankan pendidikan yang berbasis teknologi informasi dan komunikasi. Di SMA Alfa Centauri Bandung hampir semua layanannya berbasis teknologi/online dari mulai sistem informasi yang berkaitan dengan peserta didik, guru, mata pelajaran, bahkan ujian tengah semester dan akhir semester semuanya berbasis online.

Salah satu keunggulan lain yang dimiliki oleh SMA Alfa Centauri Bandung ini yaitu metode pembelajaran berbasis online. Sistem belajar ini sudah diterapkan sejak tahun 2010. Sistem ini digunakan dalam proses pembelajaran, ujian harian, dan ujian kenaikan kelas. Sebelum pemerintah menerpakan ujian berbasis komputer atau online, SMA Alfa Centauri Bandung justru sudah melakukannya. Alasannya praktis dan efisien.SMA Alfa Centauri Bandung sudah mendapatkan akreditasi A dari tahun 2006 dan pada tahun 2013 ditunjukan sebagai pelaksana terbatas kurikulum 2013.

Letak Geografis SMA Alfa Centauri Bandung berada di Jl. Diponegoro No 48, keluruhan Cihaurgeulis, kecamatan Cibeunying Kaler, kota Bandung, provinsi Jawa Barat. Gedung sekolah SMA Alfa Centauri Bandung berdiri tepat di depan gedung RRI Bandung yang bersebelahan dengan PUSDAI Jawa Barat dan dekat sekali dengan pusat pemerintahan Provinsi Jawa Barat yaitu Gedung Sate yang kurang lebih 200meter dari lokasi sekolah. Lokasi ini sangat strategis, karena mudah diakses oleh kendaraan umum dan gerbangnya yang tepat di pinggir jalan.

\section{Perencanaan Manajemen Pembelajaran Berbasis Aplikasi Sony Sugema Digital Learning System (S2DLS) di SMA Alfa Centauri Bandung}

Perencanaan pembuatan aplikasi Sony Sugema Digital Learning System (S2DLS) dimulai pada tahun 2010. Pada tahun tersebut ketua yayasan mempunyai gagasan baru dalam proses pembelajaran, dimana ketua yayasan yang bernama $\mathrm{H}$. Sony Sugema, MBA ingin membuat sebuah media pembelajaran yang mana media tersebut bisa di pakai dimana saja dan kapan saja oleh peserta didik. Maka diluncurkanlah aplikasi Sony Sugema Digital Learning System (S2DLS) sebagai media pendukung dalam proses pembelajaran peserta didik. 
Tujuan utama dalam pembuatan aplikasi ini yaitu untuk melengkapi proses pembelajaran dan menjadi pelengkap untuk model pembelajaran yang sudah ada sebelumnya. Proses perencanaan pembuatan aplikasi ini dilatarbelakangi dengan kemajuan teknologi yang semakin berkembang dan mulai maju pada saat itu. Sampai saat ini S2DLS sudah sampai ke versi ke 3 dan sedang berusaha dikembangkan agar bisa dipakai di android.

Konten-konten yang ada di dalam aplikasi Sony Sugema Digital Learning System (S2DLS) akan di jelaskan di bawah ini.

Tabel 1. Konten Aplikasi Sony Sugema Digital Learning System (S2DLS)

\begin{tabular}{ccl}
\hline No & \multicolumn{1}{c}{ Konten S2DLS } & \multicolumn{1}{c}{ Keterangan } \\
\hline $\mathbf{1}$ & Video Pembelajaran & $\begin{array}{l}\text { Berisi tentang video mata pelajaran IPA dan } \\
\text { IPS atau mata pelajaran yang di UN kan. }\end{array}$ \\
\hline $\mathbf{2}$ & Video Motivasi & $\begin{array}{l}\text { Berisi tentang video motivasi belajar, agar } \\
\text { siswa dapat termotivasi dalam proses } \\
\text { pembelajarannya }\end{array}$ \\
\hline $\mathbf{3}$ & Kumpulan E-Book & $\begin{array}{l}\text { Berisi kumpulan-kumpulan e-book yang bisa } \\
\text { dibaca dan di download. }\end{array}$ \\
\hline $\mathbf{4}$ & Simulasi Try-Out & $\begin{array}{l}\text { Berisi kumpulan soal yang bisa dikerjakan } \\
\text { oleh peserta didik }\end{array}$ \\
\hline $\mathbf{5}$ & Kamus & $\begin{array}{l}\text { Berisi penerjemah bahasa Indonesia ke } \\
\text { bahasa Inggris dan sebaliknya }\end{array}$ \\
\hline $\mathbf{6}$ & Informasi Tentang PTN & $\begin{array}{l}\text { Informasi mengenai jalur masuk perguruan } \\
\text { tinggi negeri (PTN) }\end{array}$ \\
\hline
\end{tabular}

Sumber: Heryana, 2020

Berdasarkan tabel di atas diketahui bahwa konten-konten yang ada dalam aplikasi Sony Sugema Digital Learning System (S2DLS) mempunyai enam konten di dalamnya. Konten-konten tersebut memiliki fungsinya masing-masing dalam menunjang proses pembelajaran berbasis digital untuk digunakan oleh peserta didik.

\section{Faktor Pendukung dan Penghambat Manajemen Pembelajaran Berbasis Aplikasi Sony Sugema Digital Learning System (S2DLS) di SMA Alfa Centauri Bandung}

Dalam hasil wawancara yang dilakukan kepada kepala sekolah, faktor pendukung dalam proses manajemen pembelajaran berbasis aplikasi Sony Sugema Digital Learning System (S2DLS) ini diantaranya adalah faktor biaya, sarana dan prasarana dan sumber daya manusia. Selain faktor pendukung, dalam manajemen pembelajaran berbasis aplikasi Sony Sugema Digital Learning System (S2DLS) ada faktor penghambat dalam proses manajemennya. Faktor penghambatnya adalah waktu guru dalam syuting membuat video yang tidak menentu karena waktu guru yang terbatas. Faktor penghambat tersebut sering menjadi bahasan utama dalam evalusi pembelajaran berbasis aplikasi Sony Sugema Digital Learning System (S2DLS). Waktu guru yang disibukan oleh pembelajaran dalam kelas sering menjadi penghambat dalam pembuatan video dan konten yang ada di dalam aplikasi Sony Sugema Digital Learning System (S2DLS). 


\section{Perencanaan Manajemen Pembelajaran Berbasis Aplikasi Sony Sugema Digital Learning System (S2DLS) di SMA Alfa Centauri Bandung}

Perencanaan manajemen pembelajaran berbasis aplikasi Sony Sugema Digital Learning System (S2DLS) di SMA Alfa Centauri Bandung dilakukan dengan cara menganalisis kebutuhan, menentukan target, menentukan pimpinan tim dan menentukan tugas-tugas. Direncakannya aplikasi Sony Sugema Digital Learning System (S2DLS) sebagai pendukung proses pembelajaran dan bukan sebagai pengganti media pembelajaran yang sudah ada. Perencanaan ini di latarbelakangi oleh kemajuan teknologi informasi dan komunikasi yang semakin maju di era modern ini.

Perencanaan manajemen pembelajaran berbasis aplikasi Sony Sugema Digital Learning System (S2DLS) di SMA Alfa Centauri Bandung sesuai dengan teori Mulyono dari bukunya yang berjudul "Prinsip Dasar Manajemen" yang menyatakan bahwa perencanaan harus mencakup pengelolaan sumber daya manusia, modal dan alam yang dibutuhkan organisasi serta dengan perencanaan memungkinkan kepada setiap anggota organisasi untuk dapat melaksanakan tugasnya sesuai dengan tujuan dan memungkinkan pula adanya kemajuan kearah tujuan yang dapat diamati dan diukur, sehingga tindakan pengendalian dapat diambil apabila tidak ada kemajuan organisasi (Gitosudarmo \& Mulyono, 2001, p. 12).

\section{Pengorganisasian manajemen pembelajaran berbasis aplikasi Sony Sugema Digital Learning System (S2DLS) di SMA Alfa Centauri Bandung}

Pengorganisasian yang dilakukan oleh SMA Alfa Centauri Bandung dalam manajemen pembelajaran berbasis aplikasi Sony Sugema Digital Learning System (S2DLS) ini melibatkan kepala sekolah, Staf IT sebagai orang yang mengembangkan aplikasi S2DLS, staf quality control dan guru-guru mata pelajaran. Pengorganisasian ini dilakukan agar keberlangsungan aplikasi Sony Sugeme digital Learning System (S2DLS) lebih terorganisir.

Hasil penelitian tentang pengorganisasian manajemen pembelajaran berbasis aplikasi Sony Sugema Digital Learning System (S2DLS) di SMA Alfa Centauri Bandung sesuai dengan teori yang di jelaskan oleh Badrudin dalam bukunya yang berjudul "Dasar-Dasar Manajemen" yang menjelaskan bahwa pengorganisasian merupakan salah satu fungsi manajemen yang berkaitan erat dengan perencanaan dan merupakan suatu proses yang dinamis, sedangkan organisasi merupakan alat atau wadah yang statis. Pengorganisasian merupakan penentuan pekerjaan-pekerjaan yang harus dilakukan, pengelompokan tugas-tugas, dan membagi-bagikan perkerjaan kepada setiap anggota organisasi atau karyawan, penempatan departemen-departemen (sub sistem) serta penentuan hubungan lainnya (Badrudin, 2015, p. 111).

\section{Hasil Manajemen Pembelajaran Berbasis Aplikasi Sony Sugema Digital Learning System (S2DLS) di SMA Alfa Centauri Bandung}

Hasil yang dicapai dari penerapan manajemen pembelajaran berbasis aplikasi Sony Sugema Digital Learning System (S2DLS) di SMA Alfa Centauri Bandung yaitu peserta didik dapat belajar kapan saja dan dimana saja menggunakan laptop mereka menggunakan aplikasi Sony Sugema Digital 
Learning System (S2DLS), peserta didik yang ketinggalan materi akan mudah mengakses materi yang ketinggalan dalam bentuk video yang dibuat oleh guru SMA Alfa Centauri Bandung dan dengan aplikasi Sony Sugema Digital Learning System (S2DLS) sekolah akan lebih mudah mengembangkan materi dan menjadi sekolah yang berbasis pembelajaran digital.

Dengan hasil yang telah dicapai tersebut, haruslah menjadi motivasi bagi SMA Alfa Centauri Bandung untuk lebih mengembangkan manajemen pembelajaran berbasis aplikasi Sony Sugema Digital Learning System (S2DLS) untuk mempermudah belajar peserta didik dan untuk menghadapi kemajuan dunia digital yang semakin maju. Hasil yang telah dicapai tidak lepas dari proses manajemen yang baik dari mulai perencanaan sampai dengan proses evaluasi yang dilakukan.

\section{SIMPULAN}

Perencanaan manajemen pembelajaran berbasis aplikasi Sony Sugema Digital Learning System (S2DLS) dilakukan pada tahun 2010 dengan cara menganalisis data, menentukan target, menentukan pimpinan dan menentukan tugas untuk orang-orang yang berperan dalam melakukan perencanaan. Aplikasi Sony Sugema Digital Learning System S2DLS dibuat untuk menjadi pendukung proses pembelajaran bukan untuk sebagai pengganti proses pembelajaran yang sudah ada sebelumnya. Perencanaan pembuatan aplikasi Sony Sugema Digital Learning System (S2DLS) melibatkan pihak-pihak atau orang-orang dalam pembuatannya. Di antaranya ketua yayasan sebagai penggagas utama, kurikulum yang berisi materi untuk ditampilkan dalam aplikasi, staf IT sebagai pengembang serta pembuat konten dan guru sebagai pengisi konten dalam aplikasi Sony Sugema Digital Learning System (S2DLS).

Pengorganisasian dalam manajemen pembelajaran berbasis aplikasi Sony Sugema Digital Learning System (S2DLS) ini melibatkan hampir semua pihak yang ada di sekolah. Pengorganisasiannya diantaranya kepala sekolah sebagai penanggungjawab dalam proses pelaksanaan dan penerapan aplikasi S2DLS dalam manajemen pembelajarannya, staf quality control (qc) sebagai orang yang mengontrol dan menguji kelayakan konten untuk dimasukan ke dalam aplikasi S2DLS, staf IT sebagai pengedit, pengupload dan pengembang aplikasi S2DLS dan guru sebagai pengisi konten aplikasi S2DLS.

Faktor pendukung dalam manajemen pembelajaran berbasis aplikasi Sony Sugema Digital Learning System (S2DLS) di antaranya: faktor keuangan yang mendukung, sarana prasarana yang memadai dan sumber daya manusia di sekolah yang memungkinkan. Selain faktor pendukung, ada juga faktor penghambat dalam manajemen pembelajaran berbasis aplikasi Sony Sugema Digital Learning System (S2DLS) adalah waktu guru yang tidak menentu untuk syuting video dikarenakan sibuk dengan pembelajaran di kelas.

Hasil dari penerapan manajemen pembelajaran berbasis aplikasi Sony Sugema Digital Learning System (S2DLS) di SMA Afa Centauri Bandung adalah aplikasi ini dapat meningkatkan minat belajar peserta didik, lebih mudah bagi pendidik dalam mengembangkan bahan ajar dan sumber belajar lebih mudah di akses. 


\section{REFERENSI}

Badrudin, B. (2015). Dasar-Dasar Manajemen. Alfabeta.

Gitosudarmo, I., \& Mulyono, A. (2001). Prinsip Dasar Manajemen. BPFE.

Hanifah, H. (2018). Penerapan Manajemen Program Pembelajaran Bagi Guru Paud Dalam Meningkatkan Kinerja Pendidik. Comm-Edu (Community Education Journal), 1(3), 24-29. https://doi.org/10.22460/commedu.v1i3.1102

Moleong, L. J. (2011). Metodologi Penelitian Kualitatif. PT. Remaja Rosda Karya.

Muhasim, M. (2017). Pengaruh Teknologi Digital Terhadap Motivasi Belajar Peserta Didik. PALAPA: Jurnal Study Keislaman Dan IImu Pendidikan, 5(2), 53-77. https://doi.org/10.36088/palapa.v5i2.46

Muhson, A. (2010). Pengembangan Media Pembelajaran Berbasis Teknologi Informasi. Jurnal Pendidikan Akuntansi Indonesia, 8(2), 1-10.

https://doi.org/10.21831/jpai.v8i2.949

Munir, M. (2017). Pembelajaran Digital. Alfabeta.

Nasution, S. (2000). Berbagai Pendekatan Dalam Proses Belajar dan Mengajar. Bumi Aksara.

Syafaruddin, S., \& Nasution, I. (2005). Manajemen Pembelajaran. Quantum Teaching.

Wardani, M. A. P., Rufi'i, R., \& Harwanto, H. (2020). Penerapan Strategi Pembelajaran Berbasis ICT Terhadap Pencapaian Hasil Belajar Sistem Komputer Siswa Kelas X SMK. Faktor: Jurnal IImiah Kependidikan, 7(2), 99-106. https://doi.org/10.30998/fjik.v7i2.3459

Yuliana, Y. (2019). Inovasi Pembelajaran Melalui Teknologi Informasi : Pengembangan Model Pembelajaran Melalui Internet. Jurnal Isema : Islamic Educational Management, 4(1), 119-132. https://doi.org/10.15575/isema.v4i1.5179

Zufria, I. (2016). Pemanfaatan Media Digital (E-Learning) dalam Memaksimalkan Proses Belajar Mengajar (PBM) di Perguruan Tinggi. Nizhamiyah, 6(1), 76-103. https://doi.org/10.30821/niz.v6i1.23 